\title{
MIXED QUASI REGULARIZED VARIATIONAL INEQUALITIES
}

\author{
MUHAMMAD ASLAM NOOR
}

\begin{abstract}
In this paper, we introduce and study a new class of variational inequalities, known as mixed quasi regularized variational inequality in the setting of nonconvexity. We use the auxiliary principle technique to suggest and analyze some iterative schemes for regularized variational inequalities. We prove that the convergence of these iterative methods requires either pseudomonotonicity or partially relaxed strongly monotonicity. Our proofs of convergence are very simple. As special cases, we obtain earlier results for solving general variational inequalities involving the convex sets.
\end{abstract}

Mathematics subject classification (2000): 49J40, 90C30. points.

Key words and phrases: Variational inequalities, nonconvex sets. iterative methods, convergence, fixed

\section{REFERENCES}

[1] G. Stampacchia, Formes Bilineaires Coercitives sur les Ensembles Convexes, Comptes Rendus de l'Academie des Sciences, Paris, 258, (1964), 4413-4416.

[2] C. BAIOCCHI, A. CAPElo, Variational and Quasivariational Inequalities, John Wiley and Sons, New York, NY, 1984.

[3] F. Giannessi, A. Maugeri, Variational Inequalities and Network Equilibrium Problems, Plenum Press, New York, NY, 1995.

[4] F. Giannessi, A. Maugeri and M. S. Pardalos, Equilibrium Problems: Nonsmooth Optimization and Variational Inequality Models, Kluwer Academic Publishers, Dordrecht, Holland, 2001.

[5] R. Glowinski, J. L. Lions AND R. TRemolieres, Numerical Analysis of Variational Inequalities, North-Holland, Amsterdam, Holland, 1981.

[6] M. A. Noor, General Variational Inequalities, Applied Mathematics Letters, 1, (1988), 119-121.

[7] M. PATRIKSSON, Nonlinear Programming and Variational Inequalities: A Unified Approach, Kluwer Academic Publishers, Dordrecht, Holland, 1999.

[8] M. A. Noor, Some Recent Advances in Variational Inequalities, Part 1: Basic Concepts, New Zealand Journal of Mathematics, 26, (1997), 53-80.

[9] M. A. Noor, Some Recent Advances in Variational Inequalities, Part 2: Other Concepts, New Zealand Journal of Mathematics, 26, (1997), 229-255.

[10] M. A. Noor, New Extragradient-Type Methods for General Variational Inequalities, Journal of Mathematical Analysis and Applications, 277, (2003), 379-395.

[11] M. A. Noor, Some Developments in General Variational Inequalities, Applied Mathematics and Computation, 152, (2004), 199-277.

[12] M. A. Noor, Extragradient Methods for Pseudomonotone Variational Inequalities, Journal of Optimization Theory and Applications, 117, (2003), 475-488.

[13] F. H. Clarke, Y. S. Ledyaev, R. J. Stern and P. R. Wolenski, Nonsmooth Analysis and Control Theory, Springer Verlag, New York, NY, 1998.

[14] R. A. Poliquin, R. T. Rockafellar and L. Thibault, Local Differentiability of Distance Functions, Transaction of American Mathematical Society, 352, (2000), 5231-5249.

[15] M. A. Noor, Mixed Quasivariational Inequalities, Applied Mathematics and Computations, 146, (2004), 553-578. 
[16] M. A. NooR, Iterative Schemes for Nonconvex Variational Inequalities, Journal of Optimization Theory and Applications, 121, 385-395.

[17] M. A. Noor, Mutlivalued Regularized General Variational inequalities, Nonlinear Functional Analysis and Applications, 10, (2005), 179-190.

[18] M. A. NoOR, K. I. NOOR,Regularized Hemivariational Inequalities, Nonlinear Functional Analysis and Applications, 10, (2005).

[19] M. A. NooR, Nonconvex Mixed Quasi Variational Inequalities, Mathematics (Cluj), 47, (7) (2005), 195-207.

[20] M. A. Noor, Fundamentals of Mixed Quasivariational Inequalities, International Journal of Pure and Applied Mathematics, 15, (2004), 137-258. 